\title{
Inter-comparison of thermal measurements using ground-based sensors, UAV thermal cameras, and eddy covariance radiometers
}

\section{Alfonso Torres-Rua, Hector Nieto, Chistopher Parry, Manal Elarab, Wesley Collatz, et al.}

Alfonso Torres-Rua, Hector Nieto, Chistopher Parry, Manal Elarab, Wesley Collatz, Calvin Coopmans, Lynn McKee, Mac McKee, William Kustas, "Intercomparison of thermal measurements using ground-based sensors, UAV thermal cameras, and eddy covariance radiometers," Proc. SPIE 10664, Autonomous Air and Ground Sensing Systems for Agricultural Optimization and Phenotyping III, 106640E (16 July 2018); doi: 10.1117/12.2305832

Event: SPIE Commercial + Scientific Sensing and Imaging, 2018, Orlando, Florida, United States 


\title{
Inter-comparison of thermal measurements using ground-based sensors, UAV thermal cameras, and eddy covariance radiometers
}

\author{
Alfonso Torres-Rua*a, Hector Nieto ${ }^{\mathrm{b}}$, Christopher Parry ${ }^{\mathrm{c}}$, Manal Elarab ${ }^{\mathrm{d}}$,Wesley Collatz ${ }^{\mathrm{e}}$, Calvin \\ Coopmans ${ }^{\mathrm{a}}$, Lynn McKee ${ }^{\mathrm{c}}$, Mac McKee a, William Kustas ${ }^{\mathrm{c}}$

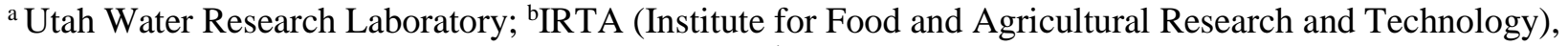 \\ 'USDA-ARS Hydrology \& Remote Sensing Lab; ${ }^{\mathrm{d}}$ MicaSense Inc.; ${ }^{\mathrm{e}}$ UC Davis Viticulture \& Enology
}

\begin{abstract}
With the increasing availability of thermal proximity sensors, UAV-borne cameras, and eddy covariance radiometers there may be an assumption that information produced by these sensors is interchangeable or compatible. This assumption is often held for estimation of agricultural parameters such as canopy and soil temperature, energy balance components, and evapotranspiration. Nevertheless, environmental conditions, calibration, and ground settings may affect the relationship between measurements from each of these thermal sensors. This work presents a comparison between proximity infrared radiometer (IRT) sensors, microbolometer thermal cameras used in UAVs, and thermal radiometers used in eddy covariance towers in an agricultural setting. The information was collected in the 2015 and 2016 irrigation seasons at a commercial vineyard located in California for the USDA Agricultural Research Service Grape Remote Sensing Atmospheric Profile and Evapotranspiration Experiment (GRAPEX) Program. Information was captured at different times during diurnal cycles, and IRT and radiometer footprint areas were calculated for comparison with UAV thermal raster information. Issues such as sensor accuracy, the location of IRT sensors, diurnal temperature changes, and surface characterizations are presented.
\end{abstract}

Keywords: sensor comparison, thermal sensors, surface temperature, high-resolution, UAV, proximity sensors.

\section{INTRODUCTION}

Estimation of thermal information for agricultural purposes is paramount for several agronomic activities, vegetation management and water applications such as canopy temperature ${ }^{1}$ soil moisture ${ }^{2}$, water stress ${ }^{3,4}$ energy balance ${ }^{5,6}$, canopy turbulence formulations ${ }^{7}$, and canopy stomatal conductance ${ }^{1}$, among others. Major satellite platforms used in agriculture (MODIS Terra and Landsat) have intensive efforts in place to enhance and calibrate thermal information ${ }^{8}$.

At field and subfield levels, thermal proximity sensors are used increasingly to monitor carefully selected locations that can provide an understanding of conditions across the farm. These sensors, known as infrared radiometers or IRT, can be placed at any elevation, distance, or angle, depending on the crop or soil feature to be monitored or tracked ${ }^{9}$. These sensors have low energy requirements and are robust against environmental conditions in tracking continuously the selected feature within its field of view (FOV). In addition, a custom configuration can be applied to IRTs to adjust for emissivity conditions ( $\sim .98$ for vegetation, $\sim 0.99$ for water); and the most typical IRT configuration, emissivity is set to 1.00 . These sensors provide excellent accuracy ( $+/-0.5$ Celsius), as described by the manufacturer.

*a.torres@aggiemail.usu.edu; phone+1435 797-0397; www.usu.edu 
Similar to the IRT sensors, radiometer sensors are used in experimental setups designed to measure energy fluxes and micrometeorological processes such as in eddy covariance towers ${ }^{10-14}$. These radiometer sensors measure short- and long-wave upwelling and down-welling radiance for calculation of energy balance fluxes. The longwave upwelling radiance measurement is of interest because it is based on measurements of infrared temperature to quantify radiance emitted from the surface using the StefanBoltzmann equation and an assumed emissivity. ${ }^{15,16}$.

Complementary to these proximity sensors are microbolometer thermal cameras for UAVs ${ }^{17,18}$. These sensors provide temperature imaging at relatively coarser resolution compared with similar-sized optical cameras. These thermal cameras are the only available imaging sensor solution for UAVs due to weight. The manufacturer's radiometric calibration plays a major role in data quality, with reported laboratory accuracies of $+/-5$ Celsius ${ }^{19}$ and $+/-1$ Celsius ${ }^{20}$ depending on the manufacturer.

\section{AREA OF STUDY}

\section{Study Site}

The area of study is a commercial vineyard field operated by E\&J Gallo and located on the outskirts of the City of Galt, Sacramento County, California. The field center is located at 38¹7'7.40"N, $121^{\circ} 6^{\prime} 58.11^{\prime \prime} \mathrm{W}$ ). This field is part of the USDA Agricultural Research Service Grape Remote Sensing Atmospheric Profile and Evapotranspiration Experiment (GRAPEX) Project ${ }^{21}$. Fig. 1 shows the location of the site in California and details of the commercial vineyard part of this study.

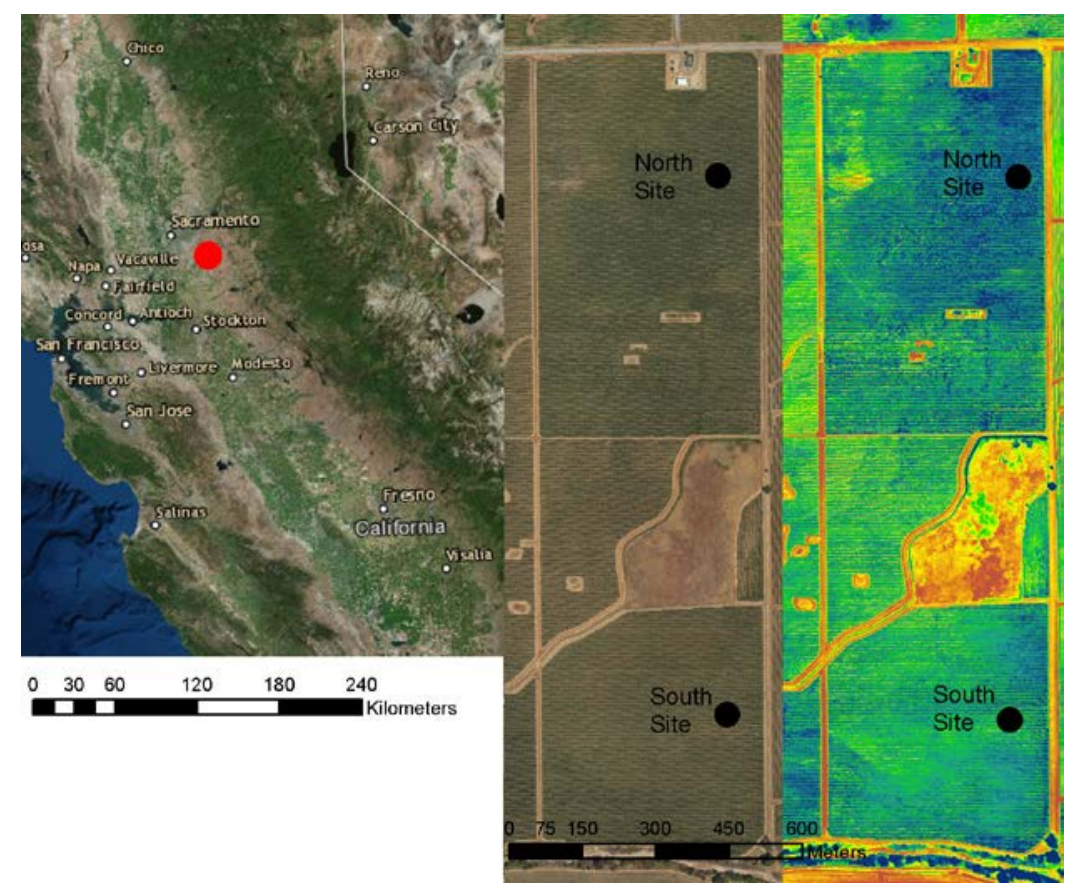

Figure 1. Location of the study area: Location in California (left) and AggieAir sUAS coverage area for all flights in RGB mosaic (center) and thermal (right)

\section{AggieAir UAV}

The AggieAir UAV is an unmanned platform developed for research applications at Utah State University. AggieAir has been used widely for remote sensing assignments in support of research in environmental settings, water resources, and agricultural applications ${ }^{22-28}$. The system incorporates a custom payload integration compatible with multiple platforms and an interchangeable sensor package that includes optical and thermal sensors. The AggieAir platforms have incorporated continuous improvements (flight times extended to 3.0 hrs. on a single battery charge, up to 3,500 m. MSL, weather sensors, etc.). To achieve 
scientific accuracy, intensive ground data collection efforts have been conducted to produce reflectance estimation protocols, address camera vignetting, assure accurate image orthorectification, etc. In addition, the optical and thermal cameras are located within a payload frame to minimize atmospheric effects (chilling) on the sensor due to flight elevations (up to 1,000 $\mathrm{m}$ above ground) and speeds ( $\sim 50 \mathrm{mph}$ ). Figure 2 shows details of the AggieAir "Minion" UAV and payloads used in this study.
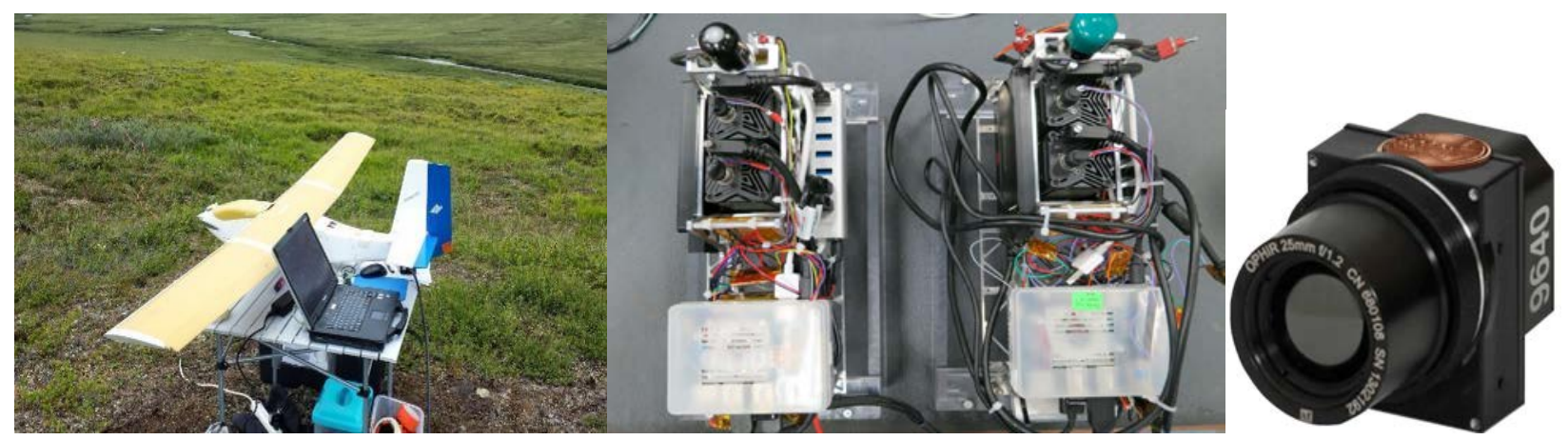

Fig. 2 Details of the AggieAir UAV. (left) Aircraft, (Center) Payload, (Left) UAV Thermal camera

\section{IRT and Eddy Covariance Sensors}

IRT sensors for this study were obtained from Apogee Inc. ${ }^{29}$ and were set up in the field as presented in the Fig. 3. The upwelling radiometer was acquired from Campbell Scientific ${ }^{30}$.

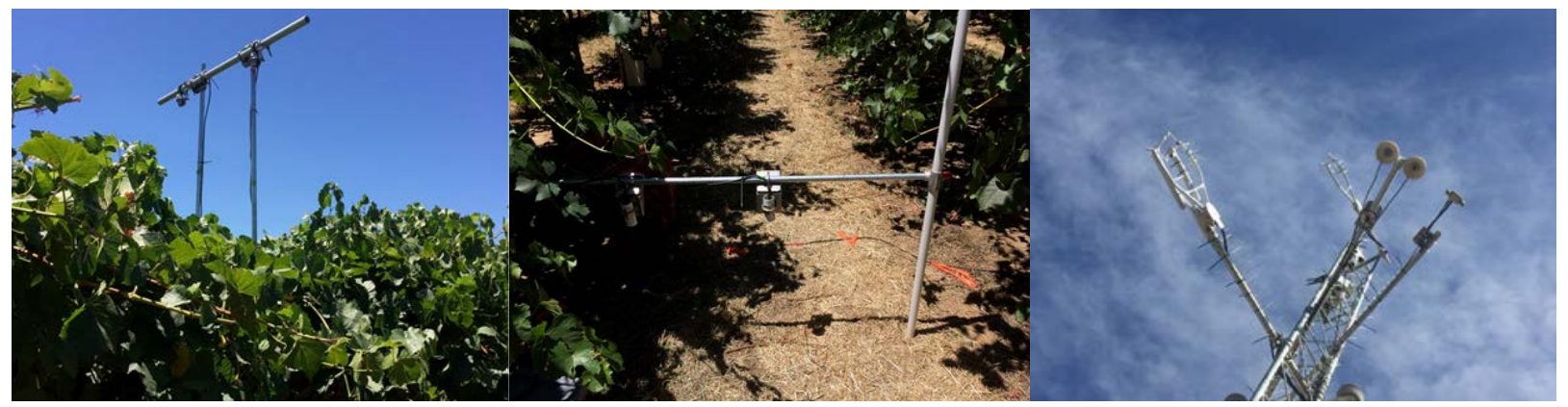

Fig 3. Details of IRT and eddy covariance radiometer setups in the study area 


\section{METHODOLOGY}

The AggieAir UAV was employed to fly over the area of study and collect thermal imagery during a 2-year campaign (2015-2016). The flight altitude was $450 \mathrm{~m}$ above ground level (AGL) and was constant for all flights. Measurements (and flights) were made at early morning (approximately a half-hour after sunrise), Landsat 8 overpass time (close to solar noon), and mid-afternoon. Exact times are presented in Table 1. Based on the study performed by Torres $^{17}$, any microbolometer-based thermal imagery requires compensation due to atmospheric conditions and elevation. A version of the general atmospheric correction, along with a vicarious calibration procedure for radiometric surface temperature, was applied to the thermal imagery in Table 1. Details of the atmospheric correction are presented at Torres ${ }^{17}$, and an example of the correction is presented in Fig. 4.

Table 1 AggieAir UAV flight times over the area of study. Times are Pacific Standard format

\begin{tabular}{|l|c|c|c|}
\hline \multicolumn{1}{|c|}{ Date } & Flight 1 & Flight 2 & Flight 3 \\
\hline June 02, 2015 & $5: 53-6: 06$ & $10: 23-10: 41$ & $13: 57-14: 17$ \\
\hline July 11, 2015 & $5: 39-5: 51$ & $10: 29-10: 42$ & $14: 00-14: 13$ \\
\hline May 02, 2016 & $6: 15-6: 23$ & $10: 55-11: 04$ & $13: 55-14: 02$ \\
\hline May 03, 2016 & $6: 45-6: 54$ & $11: 39-11: 47$ & \\
\hline
\end{tabular}



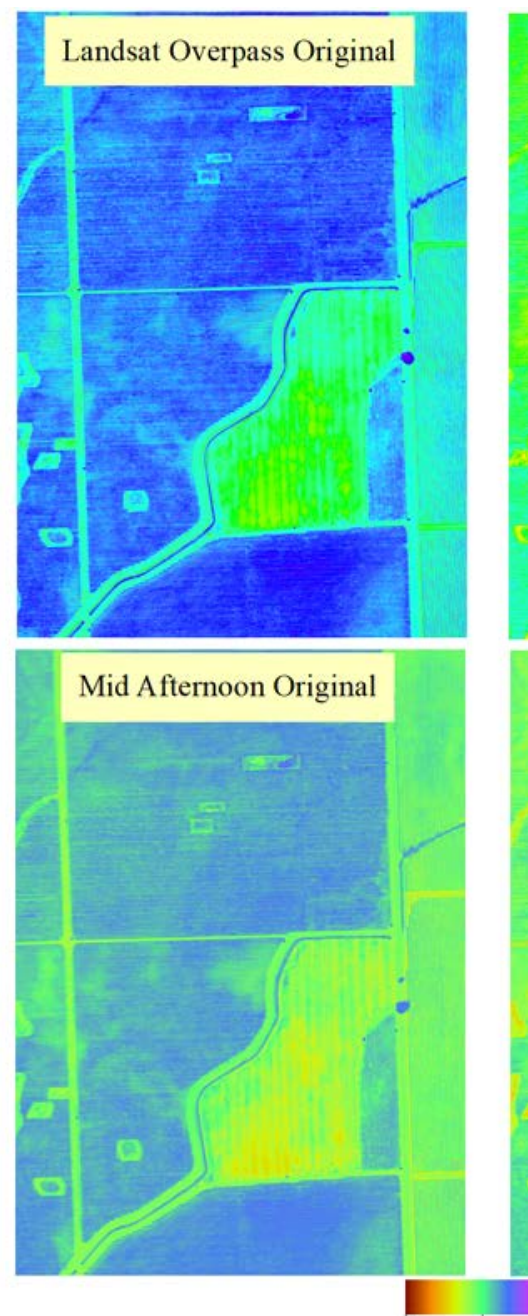

High : 60

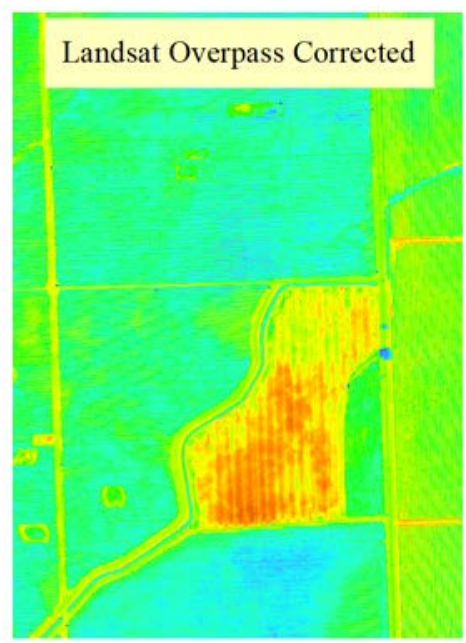

Mid Afternoon Corrected
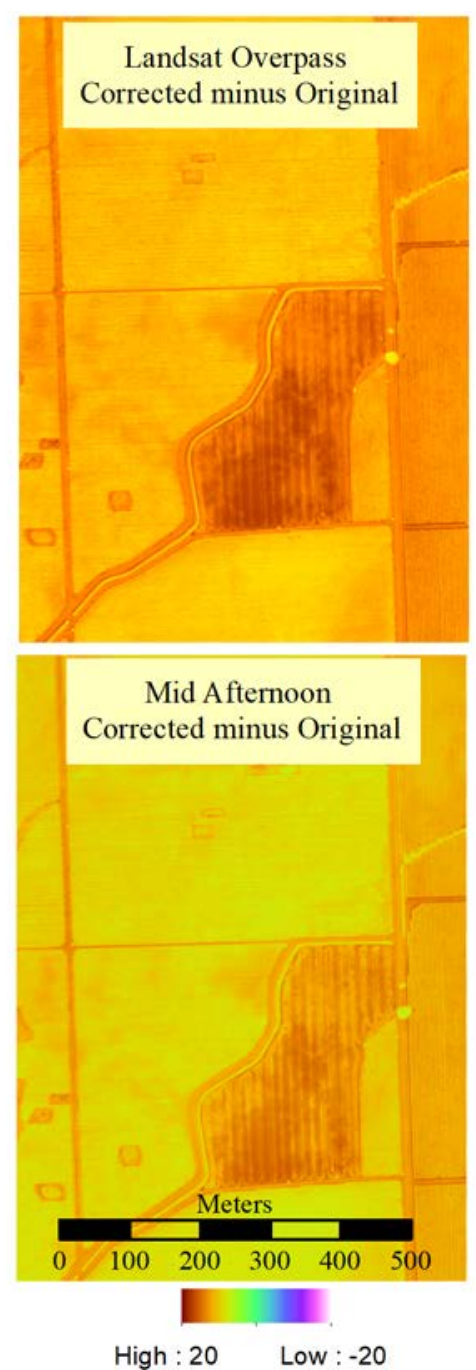

High : 20 Low : -20

Figure 4. Example of temperature image correction at $0.6 \mathrm{~m}$ resolution for May 2, 2016, using the vicarious calibration as described by Torres (2014). Information is presented for Landsat Overpass (top row) and Mid-Afternoon times (bottom row). Units are in Celsius. The left column is the UAV original temperature image, the center column is the original sUAS image after the atmospheric correction, and the right column is the difference between the corrected minus the original sUAS imagery.

To perform the multi-sensor comparison, technical details of each of the sensors were collected along with expected FOV for the proximity sensors. Table 2 presents the collected information. The IRT sensors had a typical configuration for vines (Fig. 5). For the upwelling longwave radiometer, elevation above ground was considered. Figure 6 and 7 show details of the proximity sensors footprint within the vineyard field. 
Table 2. Instruments used to collect temperature information in this study. INSTRUMENT

\section{IRT}

LW Radiometer

THERMAL CAMERA

\begin{tabular}{llll}
\hline Brand/Model & Apogee Ins/SI-111 & Campbell Sci/NR01-L & ICI/9640-P \\
Weight (gr) & 190 & 1300 & 141 \\
Image Size (pixel) & NA & NA & 640 by 480 \\
Spectral Range $(\mu \mathrm{m})$ & 8 to 14 & 4.5 to 50 & 7 to 14 \\
Spectral Band Centre $(\mu \mathrm{m})$ & 10.5 & 27.25 & 10.35 \\
Operating Range & -55 to $80^{\circ} \mathrm{C}$ & -40 to $80^{\circ} \mathrm{C}$ & -40 to $140^{\circ} \mathrm{C}$ \\
Reported Accuracy & $+/-0.5^{\circ} \mathrm{C}$ & $+/-1.0^{\circ} \mathrm{C}$ & $+/-1.0^{\circ} \mathrm{C}$ \\
Reported Emissivity & 1.0 & 1.0 & 1.0 \\
NIST Traceable? & NOT REPORTED & Int'l temp standard & NOT REPORTED \\
\hline
\end{tabular}
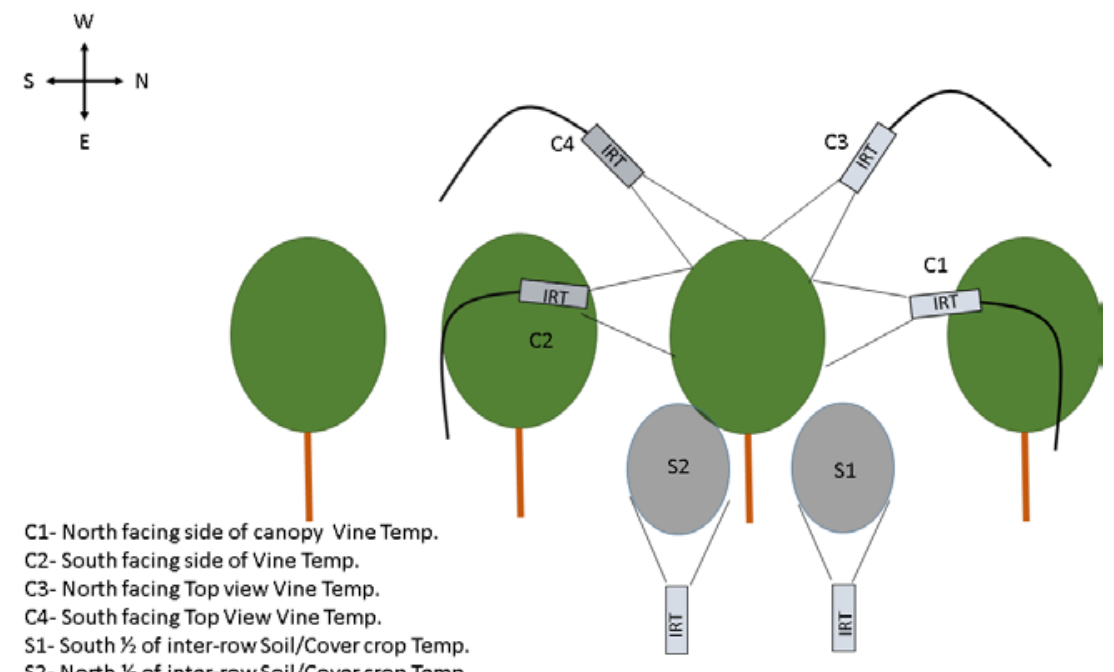

C1- North facing side of canof

C2- South facing side of Vine Temp.

C3- North facing Top view Vine Temp.

C4- South facing Top View Vine Temp.

S1- South $1 / 2$ of inter-row Soil/Cover crop Temp.

S2- North $1 / 2$ of inter-row Soil/Cover crop Temp.

Figure 5. IRT set up for this study. Note that semi-horizontal IRTs were not considered in the analysis. 


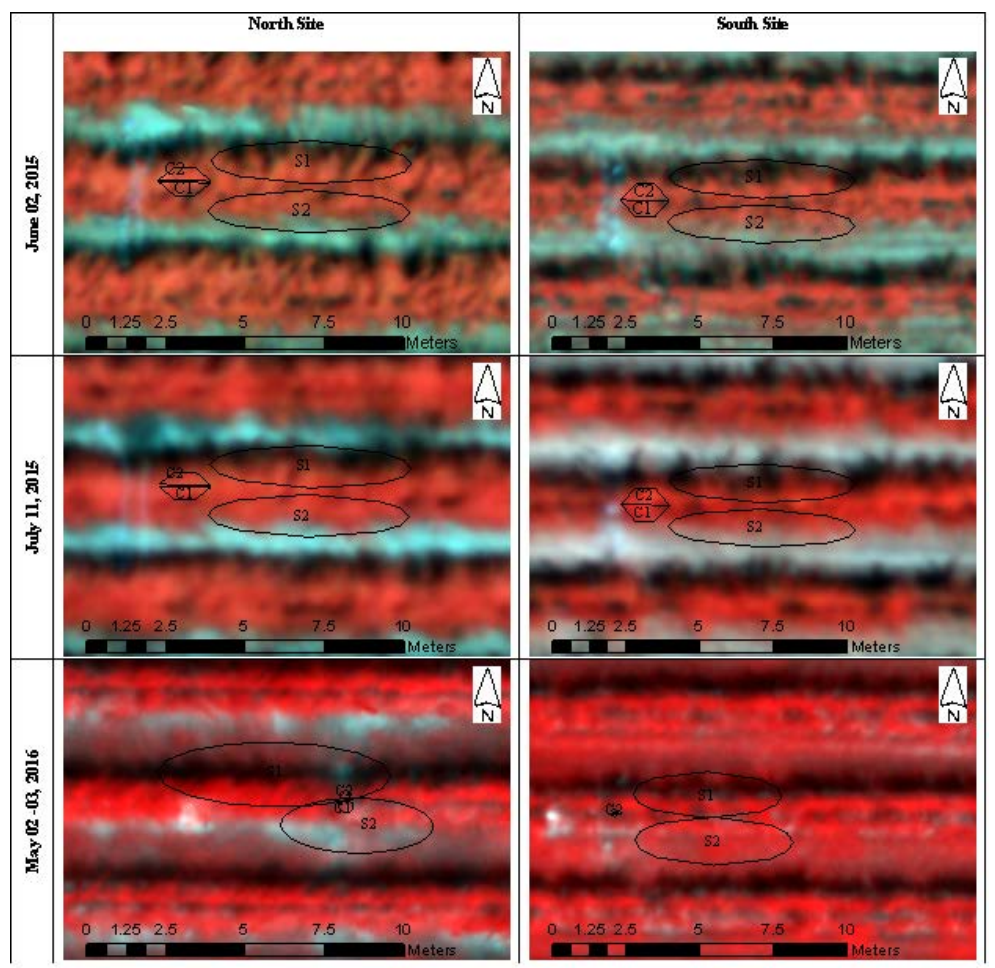

Fig. 6. IRT footprint over false color AggieAir image for the north and south monitoring locations.

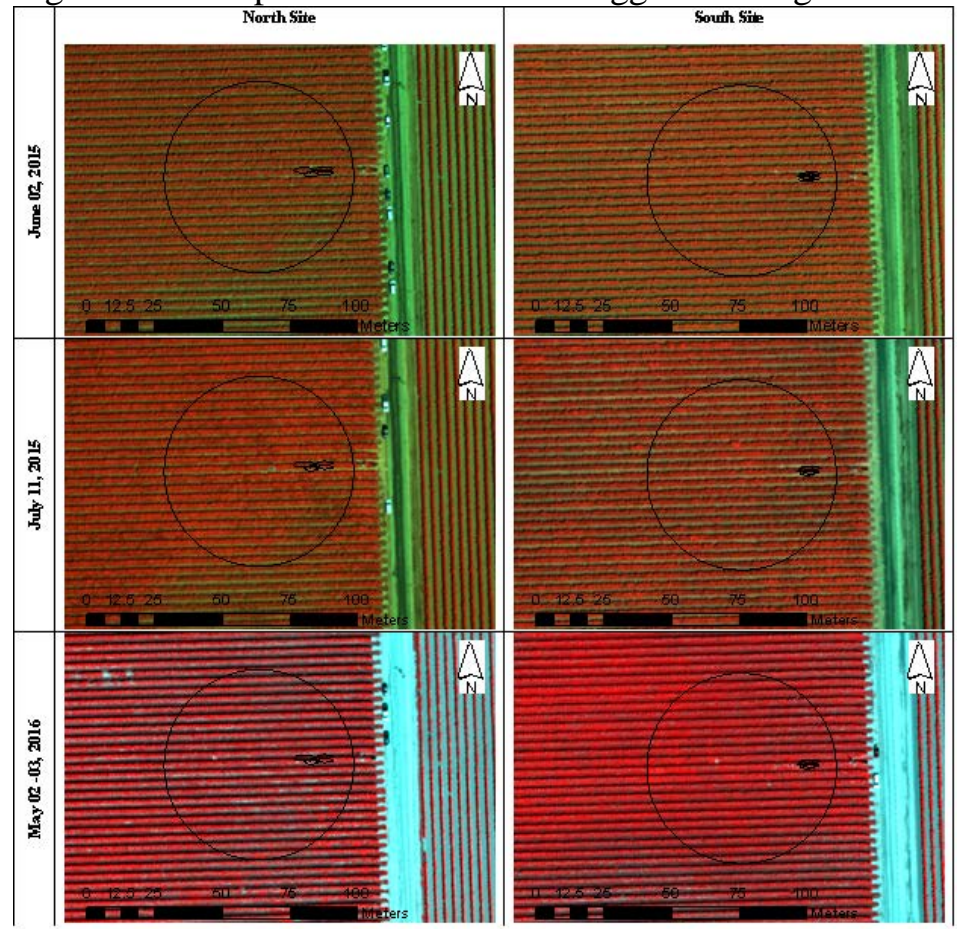

Fig. 7. Longwave radiometer footprint over false color AggieAir image for the north and south monitoring locations. 


\section{RESULTS AND DISCUSSION}

From Figs 6 and 7, it is evident that IRT and AggieAir thermal cameras will provide different temperature measurements. Effects in IRT sensors can be listed as incorporating measurements under canopy and having a strong influence from soil conditions when the canopy is partially present in the FOV. The UAV thermal camera shows manufacturer and environmental effects on the measurements during flight, image processing protocols, and point spread function. Factors that influence the upwelling radiometer measurements are emissivity assumptions due to soil and vegetation conditions, FOV, effects of the installation components (tower frame within FOV), and the weighing influence of locations closer to the center of the FOV. Having these potential effects in mind, a direct comparison of the IRT, upwelling radiometers, and AggieAir imagery is presented in Figs. 8 and 9.

As presented in Fig. 8, the relationship between IRT and Thermal Camera is not direct/linear. This is more evident in the soil IRT and AggieAir estimates. This is because, while the IRT sensor is looking under the vine canopy (Figs 5 and 6), AggieAir thermal pixels are combining canopy and soil temperatures. Canopy temperatures are closer in magnitude between IRT and AggieAir despite the IRT view angle as shown in Fig 5. Comparing AggieAir before and after vicarious calibration and with IRT data, the vicarious calibration indicates a positive influence on the thermal image data, reducing the difference between the uncorrected AggieAir camera and the IRT values. Because of the small IRT FOV dimensions, it is expected that AggieAir data is affected by its Point Spread Function, which causes a smoothing of the temperature image information. Additional efforts can be put into thermal sharpening based on existing methodologies.

Similar results can be seen in Fig. 9 for the comparison between the upwelling radiometer and the AggieAir data before and after vicarious calibration. Because of the radiometer footprint ( $70 \mathrm{~m}$ diameter), Point Spread Function influence is minimized. Fig. 9 shows that AggieAir and the Upwelling Radiance Sensor have a direct relationship, less convoluted than with IRT measurements. The impact of the AggieAir vicarious calibration can be seen clearly in the bottom row of Fig. 9, where AggieAir vicarious calibration reduced the difference between the Upwelling Radiance Sensor and AggieAir average temperature. Still, additional efforts are required to determine the nature of the differences between these two sensors. 


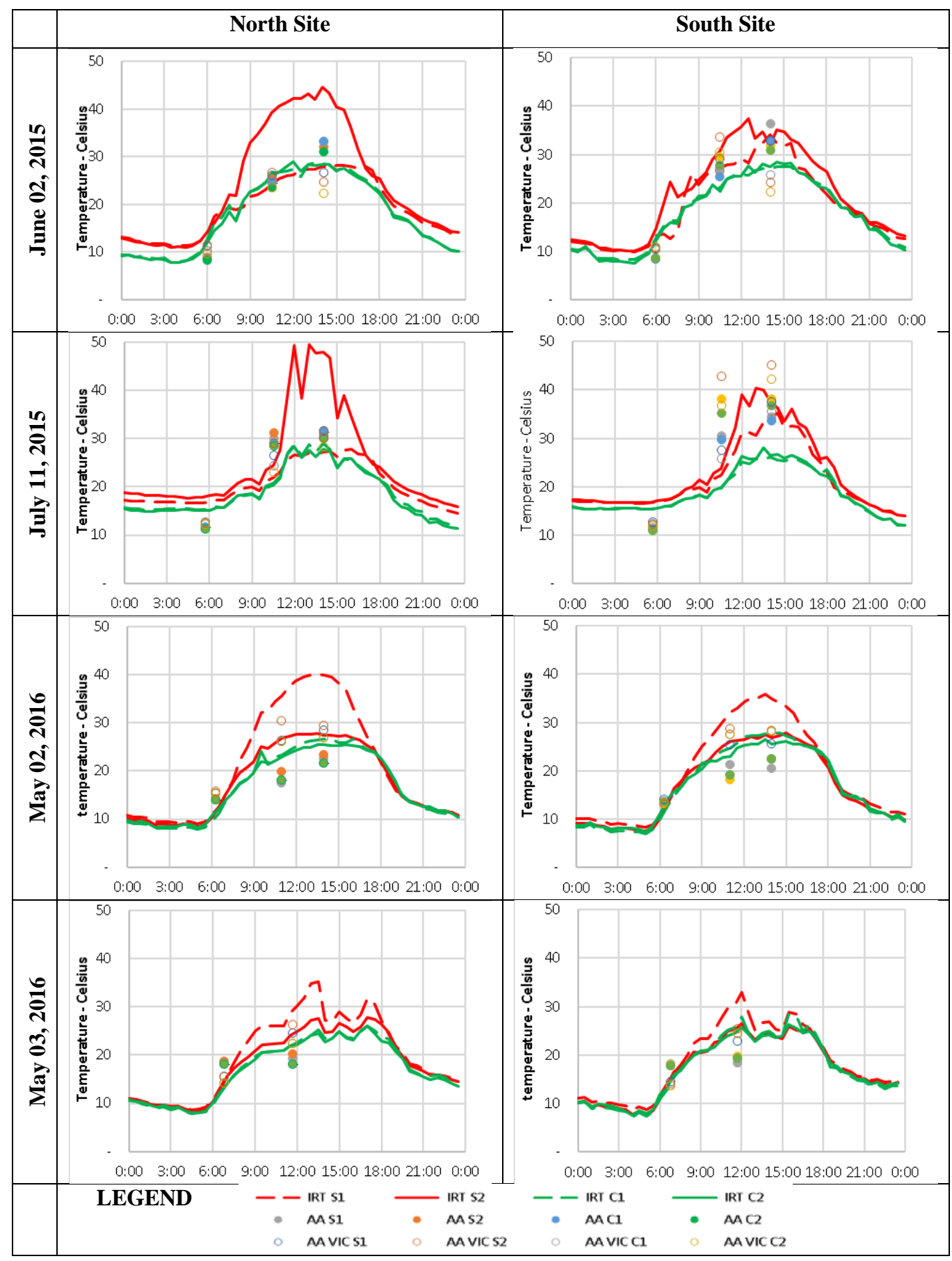

Fig 8. IRT and AggieAir before and after vicarious atmospheric calibration for each of the UAV flights in California (lines represent IRT temperature diurnal fluxes, solid dots are AggieAir before calibration, hollow dots are AggieAir thermal data after vicarious calibration). Time is Pacific Standard 


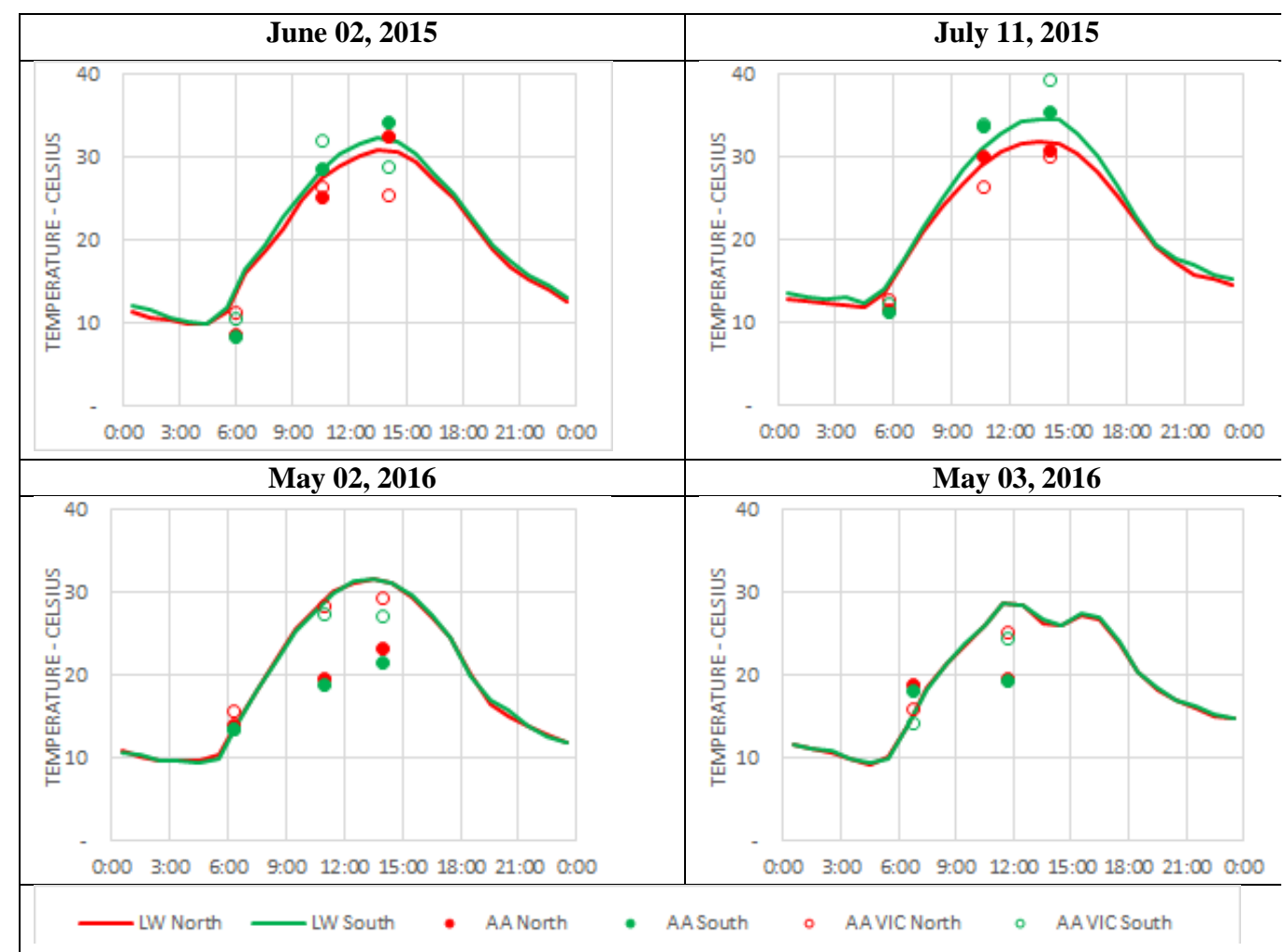

Fig 9. Eddy Covariance Tower Upwelling Radiance vs. AggieAir Temperatures. Red color indicates measurements in the north side of the field and green color at the south.

\section{CONCLUSIONS}

Scientific applications of thermal sensors, regardless of their nature, require intercomparing and validation of temperature information. This study presents a comparison of infrared temperature IRT sensors, upwelling radiance sensors, and microbolometer UAV cameras such as the ones carried by AggieAir. The results indicate that field sensor settings (over/under canopy), environmental conditions (e.g. elevation of UAV), and sensor FOV have a significant impact on the comparison of thermal information. The IRT FOV makes it necessary to improve the imaging thermal information by using sharpening techniques, thus minimizing the thermal camera point spread function influence. In eddy covariance upwelling, the effects of the vicarious calibration are more visible, showing its positive impact to the thermal imagery. Future work will evaluate sharpening thermal imagery information against IRT sensors and the suitability of eddy covariance upwelling radiance to improve vicarious calibration of UAV thermal information.

\section{ACKNOWLEDGMENTS}

This project was financially supported under Cooperative Agreement No. 58-8042-7-006 from the U.S. Department of Agriculture, from NASA under award No 200906 NNX17AF51G, and by the Utah Water Research Laboratory at Utah State University. The authors wish to thank E\&J Gallo Winery for their continued collaborative support of this research, and the AggieAir UAV Remote Sensing Group at the Utah Water Research Laboratory for their UAV technology and skill and hard work in acquiring the scientific quality, high-resolution aerial imagery used in this project. 


\section{REFERENCES}

[1] Blonquist, J. M., JR., Norman, J. M. AND BugBeE, B., “AutOMATED MEASUREMENT OF CANOPY STOMATAL CONDUCTANCE BASED ON INFRARED TEMPERATURE,” AGRIC. FOR. METEOROL. 149(12), 2183-2197 (2009).

[2] Dong, J., STEele-Dunne, S. C., OCHSNER, T. E. AND VAN DE GiESEN, N., "Determining SOIL MOISTURE AND SOIL PROPERTIES IN VEGETATED AREAS BY ASSIMILATING SOIL TEMPERATURES,” WATER RESOUR. RES. 52(6), 4280-4300 (2016).

[3] BAJWA, S. G. AND VORIES, E. D., "SPECTRAL RESPONSE OF COTTON CANOPY TO WATER STRESS," PRoceEdings of the ASAE ANNUAL MEETING, 61064 (2006).

[4] JACKSON, R. D., IDSO, S. B., REginAtO, R. J. AND PinTER, P. J., “CANOPY TEMPERATURE AS A CROP WATER STRESS INDICATOR,” WATER RESOUR. RES. 17(4), 1133-1138 (1981).

[5] Cammalleri, C., Anderson, M. C., Ciraolo, G., D’Urso, G., Kustas, W. P., La Loggia, G. AND MINACAPILLI, M., “APPLICATIONS OF A REMOTE SENSING-BASED TWO-SOURCE ENERGY BALANCE ALGORITHM FOR MAPPING SURFACE FLUXES WITHOUT IN SITU AIR TEMPERATURE OBSERVATIONS,” REMOTE SENS. ENVIRON. 124, 502-515 (2012).

[6] Colaizzi, P. D., Kustas, W. P., ANDERson, M. C., AgAM, N., TOlK, J. A., EvetT, S. R., Howell, T. A., GOWDA, P. H. AND O’SHAUGHNESSY, S. A., “TWO-SOURCE ENERGY BALANCE MODEL ESTIMATES OF EVAPOTRANSPIRATION USING COMPONENT AND COMPOSITE SURFACE TEMPERATURES,” ADV. WATER RESOUR. 50, 134-151 (2012).

[7] Wilson, T. B., Norman, J. M., Bland, W. L. AND KuCHARIK, C. J., "Evaluation Of THE IMPORTANCE OF LAGRANGIAN CANOPY TURBULENCE FORMULATIONS IN A SOIL-PLANTATMOSPHERE MODEL,” AGRIC. FOR. METEOROL. 115(1-2), 51-69 (2003).

[8] BARSI, J. A., SCHOTT, J. R., HOOK, S. J., RAQUENO, N. G., MARKHAM, B. L. AND RADOCINSKI, R. G., "LANDSAT-8 THERMAL INFRARED SENSOR (TIRS) VICARIOUS RADIOMETRIC CALIBRATION," REMOTE SENSING 6(11), 11607-11626 (2014).

[9] “APOGEE INSTRUMENTS.”, <HTTP://WWW.APOGEEINSTRUMENTS.COM/INFRAREDRADIOMETER/> (24 FEBRUARY 2017 ).

[10] SCANLON, T. M. AND KUSTAS, W. P., "PARTITIONING CARBON DIOXIDE AND WATER VAPOR FLUXES USING CORRELATION ANALYSIS,” AGRIC. FOR. METEOROL. 150(1), 89-99 (2010).

[11] SenAy, G. B., Friedrichs, M., Singh, R. K. AND VelPuRI, N. M., "Evaluating LandSAt 8 EVAPOTRANSPIRATION FOR WATER USE MAPPING IN THE COLORADO RIVER BASIN,” REMOTE SENS. ENVIRON. 185, 171-185 (2016).

[12] DREXleR, J. Z., SNYDER, R. L., SPANO, D. AND PAW U, K. T., “A REVIEW OF MODELS AND MICROMETEOROLOGICAL METHODS USED TO ESTIMATE WETLAND EVAPOTRANSPIRATION,” HYDROL. PROCESS. 18(11), 2071-2101 (2004).

[13] Anderson, R. G., Alfieri, J. G., TiradO-Corbalá, R., GARTUng, J., McKeE, L. G., Prueger, J. H., WANG, D., AYARS, J. E. AND KUSTAS, W. P., “ASSESSING FAO-56 DUAL CROP COEFFICIENTS USING EDDY COVARIANCE FLUX PARTITIONING,” AGRIC. WATER MANAGE. 179, 92-102 (2017).

[14] CHANG, Y., Ding, Y., ZHAO, Q. AND ZHANG, S., "REMOTE ESTIMATION OF TERRESTRIAL EVAPOTRANSPIRATION BY LANDSAT 5 TM AND THE SEBAL MODEL IN COLD AND HIGH-ALTITUDE REGIONS: A CASE STUDY OF THE UPPER REACH OF THE SHULE RIVER BASIN, CHINA,” HYDROL. PROCESS. 31(3), 514-524 (2017).

[15] Moureaux, C., Ceschia, E., Arriga, N., BÉZiat, P., Eugster, W., Kutsch, W. L. ANd Pattey, E., “EDDY COVARIANCE MEASUREMENTS OVER CROPS,” [EDDY COVARIANCE], 319-331 (2011).

[16] FoKen, T., Aubinet, M. AND Leuning, R., “THE EdDy COVARIANCE METHOD,” [EdDY COVARIANCE], 1-19 (2011).

[17] TORRES-RUA, A., "ViCARIOUS CALIBRATION OF SUAS MicrobOlOMETER TEMPERATURE IMAGERY FOR ESTIMATION OF RADIOMETRIC LAND SURFACE TEMPERATURE,” SENSORS 17(7) (2017).

[18] DE VRIES, J., "IN-SITU CALIBRATION OF A MICROBOLOMETER CAMERA FOR THE STUDY OF LARGESCALE FIRES,” THERMOSENSE: THERMAL INFRARED APPLICATIONS XXXV (2013). 
[19] FLIR SYSTEMS, I., "FLIR SYSTEMS | THERMAL IMAGING, NiGHT VISION AND INFRARED CAMERA SYSTEMS," < HTTP://WWW.FLIR.COM/HOME/> (22 DECEMBER 2016 ).

[20] "WE ARE IR!”, < HTTPS://WWW.INFRAREDCAMERASINC.COM/> (14 MARCH 2018 ).

[21] “GRAPEX HOME : USDA ARS.”, <HTTPS://WWW.ARS.USDA.GOV/NORTHEAST-AREA/BELTSVILLEMD-BARC/BELTSVILLE-AGRICULTURAL-RESEARCH-CENTER/HYDROLOGY-AND-REMOTE-SENSINGLABORATORY/DOCS/GRAPEX/GRAPEX-HOME/> (15 MARCH 2018 ).

[22] Hassan-Esfahani, L., Torres-Rua, A., Jensen, A. And Mckee, M., "Spatial Root Zone Soil WATER CONTENT ESTIMATION IN AGRICULTURAL LANDS USING BAYESIAN-BASED ARTIFICIAL NEURAL NETWORKS AND HigH- RESOlUTION VisuAL, NIR, AND THERMAL IMAGERY,” IRRIG. AND DRAIN. (2017).

[23] Al-Arab, M., Torres-Rua, A., Ticlavilca, A., Jensen, A. And McKee, M., “Use OF HighRESOLUTION MULTISPECTRAL IMAGERY FROM AN UNMANNED AERIAL VEHICLE IN PRECISION AGRICULTURE,” 2013 IEEE INTERNATIONAL GEOSCIENCE AND REMOTE SENSING SYMPOSIUM IGARSS, 2852-2855, IEEEXPLORE.IEEE.ORG (2013).

[24] Leila HaSSAN-ESFAHANI, U. S. U. AND AuthORS., "High ReSOlution Multi-SPECTRAL IMAGERY AND LEARNING MACHINES IN PRECISION IRRIGATION WATER MANAGEMENT” (2015).

[25] JENSEN, A. M., MCKEE, M. AND CHEN, Y., "CALIBRATING THERMAL IMAGERY FROM AN UNMANNED AERIAL SYSTEM - AGGIEAIR,” 2013 IEEE INTERNATIONAL GEOSCIENCE AND REMOTE SENSING SYMPOSIUM - IGARSS, 542-545(2013).

[26] Elarab, M., Ticlavilca, A. M., Torres-Rua, A. F., Maslova, I. AND McKee, M., "Estimating CHLOROPHYLL WITH THERMAL AND BROADBAND MULTISPECTRAL HIGH RESOLUTION IMAGERY FROM AN UNMANNED AERIAL SYSTEM USING RELEVANCE VECTOR MACHINES FOR PRECISION AGRICUlTURE,” INT. J. APPL. EARTH OBS. GEOINF. 43, 32-42 (2015).

[27] ChaO, H., Austin, M., HAN, Y., Chen, Y. AND MCKeE, M., “AggieAir: TOWARds Low-COST COOPERATIVE MultisPeCTRAL REMOTE SENSING USING SMALl UNMANNED AirCRAFT SYSTEMS,” [ADVANCES IN GEOSCIENCE AND REMOTE SENSING] (2009).

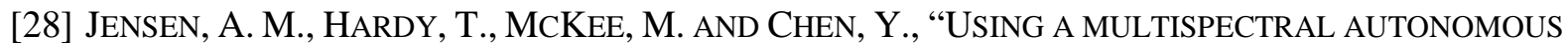
UNMANNED AERIAL REMOTE SENSING PLATFORM (AGGIEAIR) FOR RIPARIAN AND WETLANDS APPLICATIONS,” 2011 IEEE INTERNATIONAL GEOSCIENCE AND REMOTE SENSING SYMPOSIUM (2011).

[29] “APOGEE INSTRUMENTS.”, <HTTPS://WWW.APOGEEINSTRUMENTS.COM/> (15 MARCH 2018 ).

[30] "RUGGED MONITORING - MEASUREMENT AND CONTROL INSTRUMENTATION FOR ANY APPLICATION.”, <HTTP://WWW.CAMPBELLSCI.COM//> (15 MARCH 2018 ). 